\title{
Second graders articulating ideas about linear functional relationships
}

\author{
María C. Cañadas, Bárbara M. Brizuela, \& Maria Blanton
}

María C. Cañadas (corresponding author)

mconsu@ugr.es

Universidad de Granada

Departamento Didáctica de la Matemática. Facultad de Ciencias de la Educación. Campus de la Cartuja, s/n

18071 Granada

SPAIN

Bárbara M. Brizuela

Barbara.Brizuela@tufts.edu

Tufts University

Department of Education

12 Upper Campus Rd., Paige Hall

Medford, MA 02155

UNITED STATES

Maria Blanton

maria_blanton@terc.edu

TERC

2067 Massachusetts Ave

Cambridge, MA, 02140

UNITED STATES

\section{ABSTRACT}

In this paper we explore the ideas that second grade students articulate about functional relationships. We adopt a function-based approach to introduce elementary children to algebraic content. We present results from a design-based research study carried out with 21 second-grade students (approximately 7 years of age). We focus on a lesson from our classroom teaching experiment in which the students were working on solving a problem that involved a linear functional relationship $(y=2 x)$. From the analysis of students' written work and classroom video, we illustrate two different approaches that students adopt to express the relationships between 
two quantities. Students show fluency recontextualizing the problem posed, moving between extra-mathematical and intra-mathematical contexts.

Keywords: Quantities; Functional thinking; Early algebra; Elementary students

\section{INTRODUCTION}

We now have a strong body of research regarding what early algebra entails and how elementary students understand algebraic concepts. Recent research challenges so-called limitations in children's capacities to work with algebraic topics (Brizuela \& Martinez, 2012; Cai \& Knuth, 2011; Molina \& Ambrose, 2008). As summarized elsewhere (e.g., Blanton, Stephens, Knuth, Gardiner, Isler, \& Kim, 2015), these capacities concern children's ability to develop relational thinking; use different representations to express generalizations; represent verbal statements as algebraic equations; and reason about and represent relationships between abstract quantities of physical measures.

Some of the difficulties with algebra found at the secondary level concern students' understanding of the relationship between two data sets (MacGregor \& Stacey, 1995; Warren, 2000). This understanding is key from a functions based approach, which we adopt in this paper. As Schliemann, Carraher, and Brizuela (2012) observed, "a functions-based approach to early algebra relies on the importance accorded to sets of values and to ordered pairs from a domain and target" (p. 110).

In this paper, we explore how young elementary school children in second grade (around 7 years of age) understand and represent functional relationships. We present a series of classroom episodes in which children are working with a function of the type $y=2 x$. 
Traditionally, the formal study of functions in algebra begins in secondary school (usually around seventh grade). However, in the United States (US), for example, algebra has more recently been recast as a longitudinal strand of thinking starting from the earliest grades of schooling (e.g., Common Core State Standards Initiative [CCSSI], 2010; National Council of Teachers of Mathematics [NCTM], 2000, 2006; National Mathematics Advisory Panel Report, 2008). As a result, the study of functions — an important entry point into (early) algebraic

thinking (Carraher \& Schliemann, 2007) — has been advocated in US learning standards for the elementary grades by, for example, the NCTM and the Common Core Mathematical Practices (CCSSI, 2010; NCTM, 2000).

\section{THEORETICAL FRAMEWORK}

\subsection{Early Algebra Research}

Different studies and researchers consider different ways of organizing and categorizing algebra (e.g., Bednarz, Kieran \& Lee, 1996; Blanton, Levi, Crites, \& Dougherty, 2011; Drijvers \& Hendrikus, 2003; Drijvers, Goddijn, \& Kindt, 2011; Kieran, 1996, 2004; Mason, Graham, Pimm, \& Gowar, 1985; Usiskin, 1999). Drijvers and Hendrikus (2003) highlight that the different approaches cannot be considered completely separate because algebraic activities usually involve two or more approaches, while Bednarz et al. (1996) support the importance of a balance between the different approaches. In our work, we focus on functional thinking (Blanton \& Kaput, 2011), which according to Warren and Copper (2005) is one of the major components of algebraic thinking.

The results from early algebra research have paved the way for algebraic content and practices to be introduced in curricular documents for both the early (i.e., Kindergarten) and upper (i.e., grades 3-5) elementary grades in different countries in the last decades. Similar to 
the US, countries like Australia (Australian Curriculum, Assessment and Reporting Authority, 2011), Canada (Ontario Ministry of Education and Training, 2005), Korea (Beberly, 2004, cited by Ali \& Alsayed, 2010), Japan (Watanabe, 2008), and Portugal (Canavaro, 2009; Pimentel, 2010) have made curricular recommendations regarding early algebra, endorsing an increased attention to algebraic thinking during grades K-5.

\subsection{Functional Thinking as a Strand of Early Algebra Research}

Functional thinking might be characterized as the process of building, describing, and reasoning with and about functions (Blanton et al., 2011) and is constituted by topics, procedures, and relationships concerning functions (Rico, 2006). While functional thinking includes generalizing functional relationships between quantities ${ }^{1}$ and representing and reasoning with those relationships to understand function behavior (e.g., Blanton et al., 2011), it also concerns the ideas of qualitative change, quantitative change, relationships between these changes, and using these relationships to solve problems (Warren \& Cooper, 2005).

Functions constitute a powerful concept in mathematics because they give rise to relations and transformations of mathematical concepts (Warren \& Cooper, 2005) and they are present in every aspect of quantitative science (Warren, Miller, \& Cooper, 2013). Throughout the history of mathematics, functions have served a unifying role in the mathematics curriculum (Freudenthal, 1983; Hamley, 1934; Schwartz, 1990). This has also been true in other disciplines because different contents have been introduced or tackled through functions (Seldon \& Seldon, 1992). Framed by a constructivist theory of learning, in which knowledge is gradually constructed on prior understandings, the approach we follow in our research is that functions

\footnotetext{
${ }^{1}$ In this paper we focus on functional relationships between quantities as expressed through correspondence relationships (Confrey \& Smith, 1995). This work is distinct from that in the early algebra area of quantitative reasoning such as that of Dougherty (2008) and Ellis (2007) (see Carraher \& Schliemann, 2007).
} 
constitute a way to introduce students into algebra and should be dealt with longitudinally, beginning in the early elementary grades (Carraher \& Schliemann, 2007).

\subsection{Functions for Elementary Grades}

Even though there exist different definitions of function (e.g., Ensley \& Crawley, 2006; Johnsonbaugh, 2005; Pisot \& Zamansky, 1996), there is general agreement that its elements include something that varies under certain conditions (Freudenthal, 1983) and all of these definitions include variable as a key element. Variables express a quantity that can have different values in a specific numerical set. We use here variables only to refer to unknown, covarying quantities. Functions can have more than two variables; here, we focus on a function that involves two variables. In these functions, the values of one variable (dependent variable) depend on the values of another variable (independent variable). Because of the age of students in our study, we specifically focus on a linear two-variable function that can be symbolically expressed as $f(x)=2 x,{ }^{2}$ and $x$ (the independent variable) can have values in the set of natural numbers. As a consequence, the independent variable can have values in the even number set. In this work, we focus on correspondence relationships. In a correspondence approach, the focus is on the relation between two sets and on explicitly stating a (algebraic) rule (Confrey \& Smith, 1995). In contrast, in a co-variational approach the links between domain and range are spatial and relational, and the (algebraic) rule is only "a derived characteristic" (p. 79). A covariational approach to linear functions begins with the constant first difference. Our work focuses on a correspondence approach by identifying a relationship (rule) between two quantities. For example, as we can see in Table 1, there is an underlying relationship or rule between the values of the dependent variable and those of the independent variable: you can double the first to arrive at the second.

\footnotetext{
${ }^{2}$ We are not expecting second graders represent the functional relationship symbolically in this way.
} 
Table 1. Values for independent and independent variable for the function $y=2 x$

\begin{tabular}{|c|c|}
\hline Independent variable & Dependent variable \\
\hline 1 & 2 \\
\hline 2 & 4 \\
\hline 3 & 6 \\
\hline 4 & 8 \\
\hline$\ldots$ & $\ldots$ \\
\hline
\end{tabular}

In school mathematics, the relationship depicted in Table 1 is typically represented through variable notation as $y=2 x$. There are other representations that are interesting to work with in the context of early algebra (e.g., Brizuela \& Earnest, 2008; Doorman \& Drijvers, 2011; Ensley \& Crawley, 2006). The use of natural language is useful for students in the early grades because of their familiarity with it (e.g., Radford, 2011). For example, "doubling $x$ " or "adding the same number to itself" are verbal expressions for the previous example. In some contexts, pictorial representations can also be helpful to represent a functional relationship. Our view is that children should have access to all of these forms—including variable notation—in order to develop a richer understanding of functional relationships.

\subsection{Early Elementary School Children's Functional Thinking}

Research among students in elementary grades shows that children have a lot more resources to reason about functions than was previously thought. Concerning functional thinking, there is evidence that these students are able to generalize co-varying relationships, identify functional relationships when two variables are involved, represent these relationships in different ways (including with variable notation), and reason with functional relationships to interpret problem situations (e.g., Blanton, Stephens, Knuth, Gardiner, Isler, \& Kim, 2015;

Brizuela \& Earnest, 2008; Carraher, Schliemann, Brizuela, \& Earnest, 2006; Merino, Cañadas, \& Molina, 2013; Schliemann, Carraher, \& Brizuela, 2007). 
Preliminary studies suggest that children younger than third grade can employ different representations of functions in a problem-solving context (Blanton \& Kaput, 2004; Brizuela \& Alvarado, 2010). As described elsewhere, first graders' use of function tables to organize covarying data can also serve to initiate its transformation from opaque to transparent object (Kaput, 1995), and second graders use function tables to think about data and to make conclusions involving generalizations (e.g., Brizuela \& Lara-Roth, 2002; Moss \& Beatty, 2006, 2010; Moss, Beatty, Shillolo, \& Barkin, 2008; Moss \& McNab, 2011). More recent studies (e.g., Blanton, Brizuela, Gardiner, Sawrey, Newman-Owens, 2015; Brizuela, Blanton, Gardiner, Newman-Owens, \& Sawrey, 2015a; Brizuela, Blanton, Sawrey, Newman-Owens, \& Gardiner, 2015b) offer compelling evidence that children can generalize functional relationships in relatively sophisticated ways, including using variable notation to represent relationships and reasoning with these forms as objects themselves. Collectively, these studies indicate that these resources (the representations children are able to use, the ways students coordinate co-varying data, and how they notice and express relationships between quantities) can be leveraged in instruction at the very beginning of formal schooling. We are still unearthing exactly how children think about functions in different contexts and learning environments. This paper contributes to our growing understanding of children's algebraic thinking by providing evidence of functional thinking among second grade students while they work on a problem whose underlying function can be represented as $y=2 x$. The following research questions guided our study:

In what ways do second grade students articulate their ideas about a problem intended for them to explore functional relationships? And in what ways were these relationships expressed and represented? 


\section{THE STUDY}

\subsection{Participants}

In this paper, we focus on a classroom of 21 second-grade students (11 girls and 10 boys) who participated in our study. This class was intentionally selected because of the teacher's interest in participating in our study and learning about different approaches to teaching and learning mathematics. The students attended a public K-5 elementary school in an urban center of the Northeastern US. At the time of the study, a majority of the school population was either African American (47.3\%) or Latino (46.8\%). Additionally, $77.8 \%$ of students in the school were on free or reduced lunch. On state-mandated standardized assessments in mathematics, $40 \%$ of third grade students were considered "needing improvement" and 52\% were considered "warning/failing."

\subsection{Procedure}

We used design-based research (Kelly, 2003) to develop and carry out classroom teaching experiments that involved eight weeks of classroom instruction organized into two 4week cycles, along with selected student interviews before, during, and after the two cycles. Students were selected for interviews through a combination of teacher nominations and research identification of students who were active participants and articulate about their mathematical thinking, whether or not they were always accurate. In this paper, we will focus on classroom data, and will not report on the results of our interviews. Table 2 summarizes the structure of the classroom teaching experiment. 
Table 2. The Classroom Teaching Experiment.

\begin{tabular}{|c|c|c|c|c|c|}
\hline Activity & $\begin{array}{c}\text { Pre- } \\
\text { interview }\end{array}$ & $\begin{array}{c}\text { Cycle 1 (8 } \\
\text { lessons in 4 } \\
\text { weeks) }\end{array}$ & $\begin{array}{c}\text { Mid- } \\
\text { interview }\end{array}$ & $\begin{array}{c}\text { Cycle 2 (8 } \\
\text { lessons in } \\
4 \text { weeks })\end{array}$ & $\begin{array}{c}\text { Post- } \\
\text { interview }\end{array}$ \\
\hline $\begin{array}{c}\text { Function } \\
\text { type } \\
\text { focused } \\
\text { on in the } \\
\text { tasks }\end{array}$ & $y=x$ & $\begin{array}{c}y=m x, \\
\text { represented } \\
\text { additively } \\
\left(\begin{array}{c}\text { e.g., } y=2 x \\
\text { represented } \\
\text { as } y=x+x)\end{array}\right.\end{array}$ & $y=x+b$ & $y=x+b$ & $\begin{array}{l}y=m x \\
y=m x+b\end{array}$ \\
\hline
\end{tabular}

The research team taught lessons focused on solving function tasks in the second grade classroom twice a week for eight weeks. They also conducted the individual interviews. Each lesson was videotaped using two video cameras. During the lessons, one of the research team members introduced the lesson to the students and guided the whole-group sessions. Two other members of the research team observed and videotaped the whole- and small-group work. During these lessons, the regular classroom teacher was a participant observer, bringing up clarifying questions or comments for the students, and making connections to the children's mathematics curriculum and prior activities the children had worked on with her.

Data for the present study are drawn from Lesson 4, the Birthday Party Tables problem, in our classroom teaching experiment. In Table 3, we present an overview of the activities that took place prior to and during this lesson. The specific version of the problem implemented used the context of Brady's birthday party (adapted from Blanton et al., 2015): "Brady is going to celebrate his birthday at school and he wants to make sure that he has enough chairs for all his friends. The tables at his school are square. Only two people can sit at each table. There is a rule at the school that no one can sit at the ends of the table." Other researchers have used similar versions of this problem (see e.g., Carraher, Martinez, \& Schliemann, 2008; Martinez \& Brizuela, 2006; Nemirovsky, 1996). This specific problem was included because it involves a 
doubling relationship between the two variables involved, which we thought would be accessible to at least some of the students in our study. In addition, the problem has several entry points to accommodate a range of students. For example, we anticipated that children unfamiliar or less fluent with doubling of numbers would still be able to approach the problem by counting by twos. We also anticipated that if desired we could extend the problem to include the people sitting at the ends of the table, thus transforming the relationship into a $y=2 x+2$ function. We were also interested in focusing on Lesson 4 for this study because it dealt with an extramathematical context. ${ }^{3}$ While a previous activity (Lesson 3 ) had already introduced an extramathematical context, Lesson 4 was the first activity that involved two quantities with a relationship different from the identity function. Finally, previous success with the problem with slightly older students (third grade; see Blanton et al., 2015; Carraher, Martinez, \& Schliemann, 2008; Martinez \& Brizuela, 2006) also prompted our interest in exploring younger students' approaches to this task.

Table 3. Overview of Lessons 1-4 in Classroom Teaching Experiment Implemented in Second Grade.

\begin{tabular}{|l|l|l|}
\hline Lesson and date & Activity name & \multicolumn{1}{c|}{ Description } \\
\hline Lesson 1 & Repeating pattern & Students work with color and shape patterns. They are \\
& & asked to identify, construct, and compare geometrical \\
& & patterns. Patterns involve repetition in some cases. \\
& & Position numbers as independent variables are \\
& & introduced. \\
\hline
\end{tabular}

\footnotetext{
${ }^{3}$ Chevallard (1989) defines extra-mathematical contexts as contexts where a problematic situation is raised using phenomena external to the mathematical field. That is, the objects on which the relations operate have an intended meaning beyond mathematics.
} 


\begin{tabular}{|l|l|l|}
\hline Lesson and date & \multicolumn{1}{|c|}{ Activity name } & \multicolumn{1}{c|}{ Description } \\
\hline Lesson 2 & Growing patterns & $\begin{array}{l}\text { Repeating and (functional) growing geometrical } \\
\text { patterns (with positions and drawings). Multiplicative } \\
\text { function }(y=2 x) \text { is used. Students are asked to draw } \\
\text { missing items and identify position numbers. }\end{array}$ \\
\hline Lesson 3 & Pennies in a jar & $\begin{array}{l}\text { Function using an extra-mathematical context. The } \\
\text { outline of a function table is presented to the students } \\
\text { in the handout and the students are asked to fill it out. } \\
\text { Non-consecutive items are introduced in the table. The } \\
\text { function involved is } y=x .\end{array}$ \\
\hline Lesson 4 & Attached tables & $\begin{array}{l}\text { Function in an extra-mathematical context }(y=2 x) \text {. No } \\
\text { table was included in the handout. The activity was } \\
\text { introduced through a pictorial representation. }\end{array}$ \\
\hline
\end{tabular}

The implementation of each one of the lessons followed the same structure: (a) whole group discussion, (b) small-group work on handouts, and (c) whole group discussion of students' approach to the prompts provided in the handouts. In the first part of each lesson, the researcher who was leading the classroom instruction introduced the problem, trying to ensure that most of the students understood the situation involved. In this introduction, we presented some particular consecutive cases, and then non-consecutive ones. In the second part of each lesson, nonconsecutive particular cases were presented for the small-group work. In the third, and last, part of the lesson, the whole group of students discussed their responses with us.

\subsection{Data Analysis}


We transcribed the video of the Birthday Party Tables problem (Lesson 4) during the whole group work before and after students' small-group work. We also collected and analyzed students' individual handouts. In terms of the video, we carried out a line-by-line review of the verbatim transcripts (with periodic review of the video). In doing so, we constructed a narrative account of the entire lesson. We then identified episodes during the whole group discussions at the beginning and at the end of the lesson when students used different strategies to express the relationship between the number of birthday party tables and the number of chairs. We then characterized the nature of children's algebraic reasoning related to our specific research question: what ideas did they exhibit about a problem intended for them to explore functional relationships, and in what ways were these relationships expressed and represented? In addition, we also analyzed children's written work on individual handouts with the same lens, looking for evidence related to the aforementioned research question.

\section{RESULTS}

\subsection{Whole group discussion on the Birthday Party Tables problem: "Counting by twos" and "doubling"}

The researcher leading the lesson, Bárbara, introduced the problem starting with one table (with a maximum of two chairs sitting at a table), as follows:

1. Bárbara: Brady is going to celebrate his birthday at school and he wants to make sure that he has enough chairs for all his friends... This is what the tables at the school look like. Bárbara then drew a table and two circles to represent the two chairs (see Figure 1). 
2. Bárbara: The tables at his school look like that; they are square. Only two people ${ }^{4}$ can sit at each table. There is a rule at the school that no one can sit at the ends of the table.

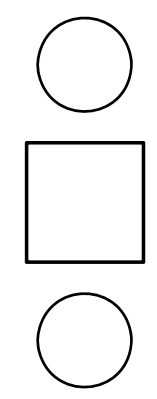

Figure 1. Example of one table.

3. Bárbara: There is one table, how many people can sit at that table?

4. Students ${ }^{5}$ : Two!

5. Bárbara: OK. What if I add another table?

6. Students: Four.

7. Bárbara: How do you know?

8. Students: I'm counting by twos.

9. Bárbara: You're counting by twos... What if there were three tables?

10. Students: Six.

11. Bárbara: You're fast. What if there were four tables?

12. Students: Eight.

As we can see from the above excerpt, with no need to draw each particular case, students provided quick answers for numbers that corresponded to two, three, and four tables. Some of the children explained that they figured this out by counting by twos (see line 8). Given that Bárbara did not probe the reasoning behind these responses, it is unclear whether the children

\footnotetext{
${ }^{4}$ We switched back and forth between referring to chairs and referring to people. Children did not seem to be bothered by this, and did the switching themselves.

${ }^{5}$ In the whole group discusstion (first and third parts of the lesson), "students" represents most of the students that participated in the lesson, who usually gave their responses at the same time.
} 
could have explained that they were counting by twos because there were two people sitting at each table. The diagram in Figure 1 had not been extended, and there were no other representations shared with the students. We therefore assume that some children were thinking: "there are two people sitting at each table, so I have to keep counting two more each time." After the first four cases (1-4 tables) were considered, Bárbara proposed the case of 10 tables without making any drawings.

13. Bárbara: Can I skip?... What if there were 10 tables?

14. Students: 20.

Bárbara skipped from four tables to 10 tables in order to avoid children focusing on the recursive relationships. The general response of the students, as a whole, was 20 right away. Given how quickly the majority of the students responded, it appears that the strategy used was not to count by twos, as they had indicated in line 8 , above.

15. Bárbara: I did not... Were you counting by twos?

16. Students: Yes (a few students responded "No"). ${ }^{6}$

17. Bárbara: How did you do that? I don't understand, how do you know?... Let me keep track of that...

Bárbara organized the information of the previous particular cases in two columns, one for the number of tables, and one for the number of chairs/people. She did not draw the table or label the columns (see Figure 2). While Bárbara was implicitly representing the "number of tables" and "number of chairs/people" in each one of the two columns, it is possible that children interpreted the two columns or lists as numbers devoid of context, without making explicit connections to the problem situation of children seated at tables. Their responses at all times focused on the numbers, and not on "number of chairs" or "number of people." While this might be a reflection

\footnotetext{
${ }^{6}$ We use parenthesis in transcription to explain something that happened in the class at the time of the conversation.
} 
of the types of questions they were asked, questions that did not necessarily call for them to explicitly talk about context (e.g., see lines 18-24), it could also be that students did not make a connection between the numbers in the table and the context from which they were derived.

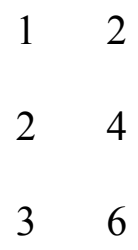

Figure 2. Organization of the information in two columns.

Bárbara asked the children to explain how they got the number of people.

18. Bárbara: You told me that you were counting by twos right? How were you counting by twos? Who can show me? James, could you show me how you were counting by twos?

19. James ${ }^{7}$ : Eight.

20. Bárbara: But there is no eight up there. Well if I put eight, should I put eight on this side, on the left or on the right [hand column $\left.{ }^{8}\right]$ ?

21. James: On the right.

22. Bárbara: On the right. James... And what should I put on the left? (Some of the students said four and others said five.)

23. Bárbara: OK, some people say four and some people say five. Who...

Students continued chattering until James stated:

24. James: You've got [to put] a four there (indicating the left column, underneath the 3, see Figure 2) because four plus four equals eight.

While the rest of the children had been voicing a "counting by twos" strategy (see line 8), James referred to a "doubling" strategy (or, as it is sometimes conceptualized in lower elementary

\footnotetext{
${ }^{7}$ All students' names in this paper are pseudonyms.

${ }^{8}$ We use brackets in transcription to complete sentences in the way that they were understood in class considering the context.
} 
grades, adding a number to itself): when justifying why four (tables) should correspond to eight (chairs/people) he said, "You've got a four there because four plus four equals eight" (see line 24).

Right after this interaction, Bárbara asked children how many people would sit at 10 tables. Some students said 20 and others said 12. At this point, we can infer that the students saying 20 people were doubling 10 or adding 10 twice (ten plus ten). Those saying 12 were probably using a "counting by twos" strategy and simply adding 10 and 2, not realizing that these were values for two different variables (10 for number of tables and two for number of people). The case of nine tables was not available to them in the information they had (see Figure 2). Had it been available, they might have been able to count on by twos down the column from the people sitting at nine tables. They instead used this strategy to count on by twos across the row, counting two on from 10. Bárbara asked the children to explain their answers.

25. James: (With his hand up.) I know the answer.

26. Bárbara: So James has a way to explain to us. Who else has a way to explain? Is it twenty or is it twelve? How could we figure that out? Thomas, you said twelve, can you explain why it's twelve? How do you know it's twelve?

27. Thomas: Because... we are adding two.

28. Bárbara: Adding two... so what did you add to get to twelve?

29. Thomas: To ten.

By "adding two," Thomas meant to add two to the number of tables (here, 10), rather than recursively adding two to successive values for the number of people (in the right hand column). Bárbara then explored Thomas's suggestion with the class.

30. Bárbara: So Thomas said that the rule is to add two. Let's see if it works. 
Bárbara turned to the table, starting with the first row and the case of one table.

31. Bárbara: How much is one plus two?

32. Students: Three.

33. Bárbara: Three. So, is that (adding two) the rule? (Pointing at the number two next to number one in the right column.) How much is two plus two (moving on to the next row and pointing to the number two on the left column)?

34. Students: Four.

35. Bárbara: How much is three plus two (pointing to the row with three tables, where three and six are paired up)?

36. Students: Five!

37. Bárbara: How much is four plus two (pointing to the row with four tables, where four and eight are paired up)?

38. Students: Six!

39. Bárbara: So is the rule to add two? Is that how you get from here (column on the left) to here (column on the right)?

At this point, Shay noticed that the rule of "counting by twos" works when you are adding successive values in the right hand column of the function table.

40. Shay: The rule is that you count by twos because two plus eight is ten (going down the right hand column from the row for four tables to the row for five tables).

41. Bárbara: But when Thomas said you were counting by twos, he thought what you have to do is you have to add two to this number (pointing at the number in the left column). Can you talk to Thomas and explain to him what you think? 
Shay explained that she figured it out because she did 10 plus 10 equals 20 for 10 tables. Bárbara asked her to check if this rule worked for the previous cases.

42. Bárbara: So, does this work for the other numbers? Let's see... Does this work for four? Can you show us?

43. Shay: You can do four plus for equals eight, three plus three equals six, two plus two equals four, one plus one equals two.

After asking other students about the rule to check if they understood Shay's explanation, Bárbara found different children supporting either 12 or 20 as the outcome for 10 tables. She then considered the two different answers for 10 tables and asked Shay to explain her rule in "words."

44. Bárbara: Could you explain in words how you get from here (pointing at the column on the left) to here (pointing at the column on the right)?

45. Shay: It's because ... the reason why I think it's 20 is because if you add... because 10 , like if you add 10 more, it is 20 .

46. Bárbara: So, what is the rule for any number of tables, what is the rule to get to the number of chairs?

47. Shay: My rule is add... two numbers together make a higher number.

Shay's answer shows that she was able to explain how to get to the correct response numerically (adding the number to itself). She was able to explain this using specific cases (for one, two, three, four, and 20). However, her articulation of the rule ("add... two numbers together make a higher number," see line 47) does not refer to the relationships between the specific quantities involved. She did not make explicit reference to the problem context; neither did Bárbara probe her at any point about what the number 20 referred to (e.g., Bárbara did not ask something like 
“the number 20 refers to 20 what?”). When Bárbara asked Shay about the rule in terms of tables and chairs, she came back to the numbers involved. For instance, she did not connect her rule to the fact that two chairs are being added for every table that is added. As mentioned earlier, neither children who were using a counting by twos strategy nor a doubling strategy made the problem context explicit in their explanations. Instead, they recontextualized the problem (Carraher \& Schliemann, 2002) from a physical to a mathematical context. The conversation with the students continued as follows.

48. Bárbara: Great. James, what were you thinking?

49. James: I think it is 20.

James agreed with Shay now, although he had previously said that 17 people could sit at 10 tables. Bárbara asked him why he had earlier said 17 and why he had changed his mind.

50. James: I counted on my fingers and then [inaudible].

51. Bárbara: OK, and what were you counting on your fingers?

52. James: Twos.

53. Bárbara: Ah, you were trying to count by twos. You were trying to continue this (Bárbara pointed down the column on the right with the quantity of people), by twos? But I tricked you because I skipped some numbers, right (i.e., jumped from four to 10 tables)?

Annita continued to articulate Shay's strategy even further, by proposing that to get one value, you should double the other value.

54. Annita: I think it's 20 because if you double one, it's two; double two is four; and double three is six.

55. Bárbara: Wow, did you hear the word she used?

56. Students: Double... 
As with Shay's explanation above, even though Annita and other students were able to identify the doubling relationship between the pairs of numbers, they did not make explicit the specific problem context related to tables and people/chairs or what the doubling had to do with the fact that two chairs/people were being added every time a table was added. In this excerpt, Bárbara highlighted that it was the first time that she had heard the word "double" used in the class and wrote ways that students characterized the relationship on the flip chart at the front of the class: "double" and "add two numbers that are the same."

The research team then proceeded to pass around handouts for the students to engage in their small-group work at their tables.

\subsection{Small-group work: continuing to use "counting by twos" and "doubling" approaches}

Each student worked in small groups on the proposed task "How many friends could be seated at 20 desks?" Students were asked to explain in written work how they found their solution. Of the 21 children in the class, only one did not provide either a response of " 40 people" or an explanation that included either implicitly or explicitly "doubling" or "counting by twos" (see Figure 5). This student told the research team member that was working with her that she had "guessed" that the answer was 10. Her written work indicates that she was drawing tables; at each table she drew 2 seats, as shown in Figure 5. She also kept track of the number of tables, numbering each of them. We infer from this that she understood the task at hand and that, perhaps, her response of " 10 " resulted from her losing track of the numbers involved. That is, she was not really "guessing," but was simply not able to articulate her reasoning in any other way. Alternatively, she may have been looking for a number that resulted in an outcome of 20 (people/desks) as we had been doing earlier in class. 


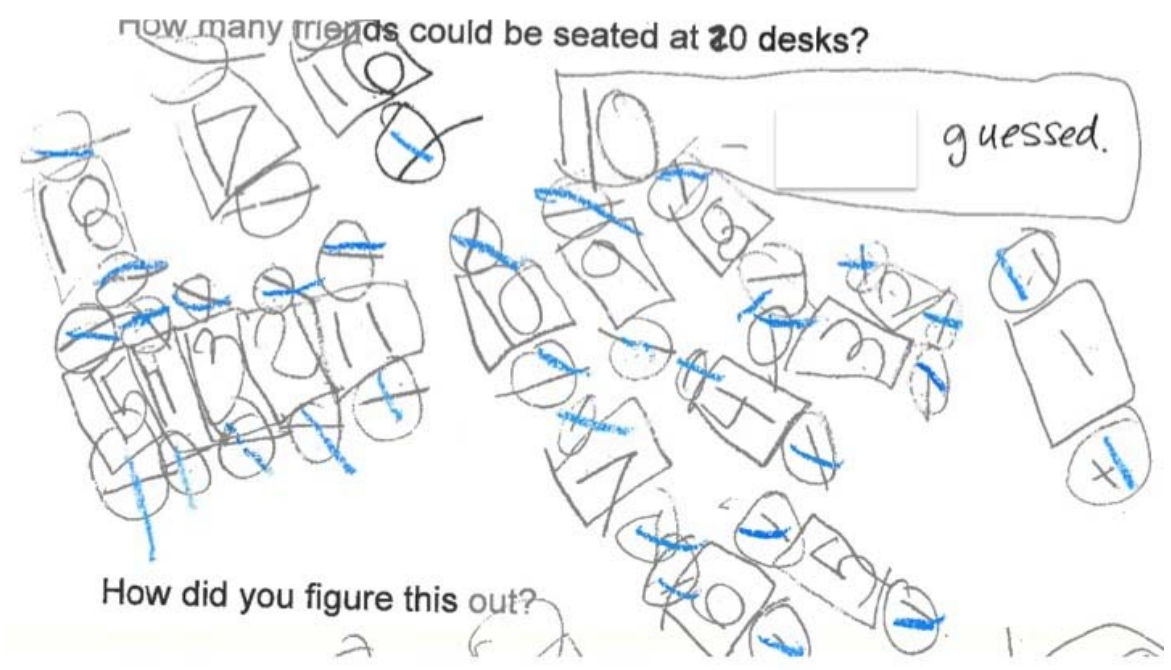

Figure 5. Student who "guessed" that the answer was ten.

Table 4 summarizes our observations made from individual handouts for the remaining 20 students in the class. In what follows, we looked for evidence of whether children were "counting by twos" and/or "doubling or counting 20 twice" as they had done during the whole group work. In most cases, students explicitly stated what strategy they used (although we don't have evidence of whether they were just stating this a posteriori or if this was actually the strategy used while working on the problem). In other cases, we inferred the strategy used based on the written work produced by the student. A student who wrote " $2,4,6,8,10,12,14,16,18$, $\ldots, 40$ ) would be considered as "counting by twos." A student who only wrote " $20+20=40 "$ would be considered as "doubling or counting 20 twice."

Of these remaining 20 students in the class, seven of them provided a complete drawing (20 tables and 40 people sitting at these tables) to answer the question. Of these seven students, four students made no explicit written reference to "people/chairs" and/or "table/desks;" two of these four students said they "counted by ones" and the other two students said that they 
"counted by twos". The other three students stated that they had counted by twos in response to the question "How did you figure this out?" (see Figure 6), and made explicit written reference to "people/chairs" and/or "table/desks". These seven children, who provided complete drawings, attended to the specific nature of the context of the problem in different ways. For instance, we hypothesize that children who produced complete drawings used the problem context to support their computation in relation to the problem by counting the number of chairs in their drawings. In addition, in describing their strategy, some of the children alluded specifically to "people/chairs" and/or "table/desks" present in the context in describing their strategy, although they may or may not have alluded to these contexts when giving the solution to the problem (40 people). For instance, it is possible that the child whose work is shown in Figure 6, and who explicitly names "desks" and "people," was influenced by the drawing he produced to describe his strategy because he described first drawing the table and people, then counting (see Figure 6).

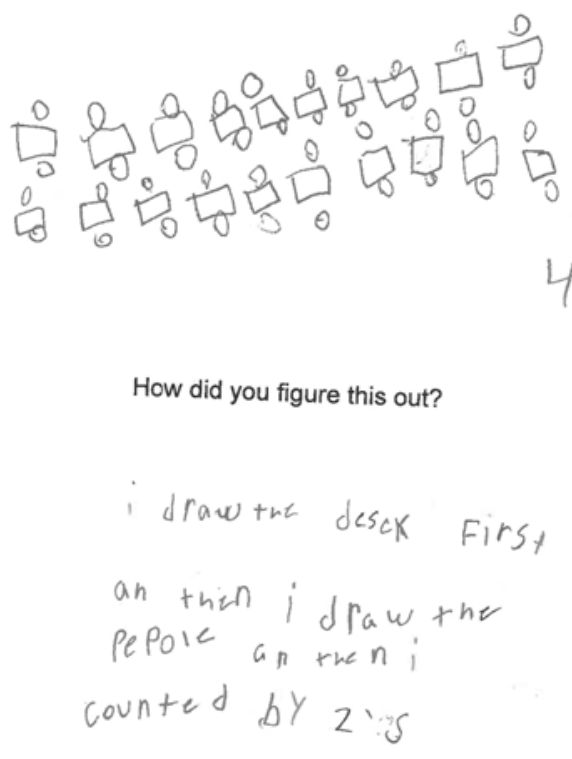

Figure 6. Complete drawing with "counting by twos" strategy. ${ }^{9}$

\footnotetext{
9 "I draw desks first and then I draw the people and then I counted by 2's."
} 
Twelve students did not include drawings, but did explain how they arrived at an answer of "40." Nine of these 12 students made no explicit verbal reference to the context of people/chairs or tables/desks. Seven of these nine students stated that they "doubled" or added “20+20.” One of these seven students did not make a drawing but instead produced a number line representation to get the result of 20+20 (see Figure 7). The remaining two students who did not make a drawing and did not refer to people/chairs and/or tables/desks included two strategies in their handouts: they "counted by twos" and also showed that they were doubling 20 to arrive at an answer of 40 (see Figure 8 for an example). Three of the 12 students who did not make a drawing did explicitly mention "people/chairs" and/or "tables/desks." One of these three students used the counting by twos strategy and the other two the "doubling or counting twenty twice" strategy.

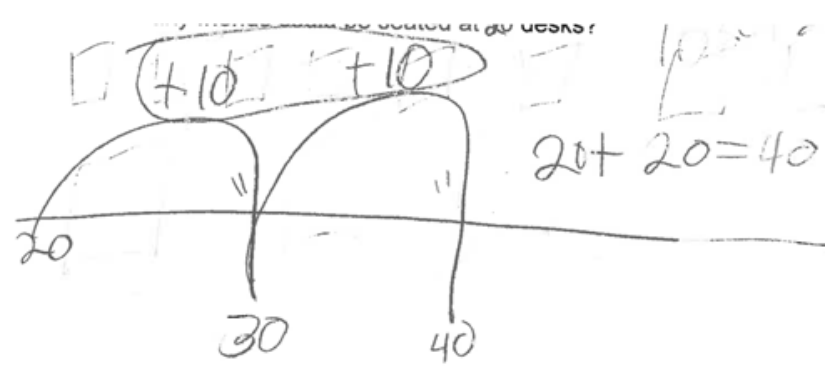

Figure 7. Use of number line to show a doubling strategy. 


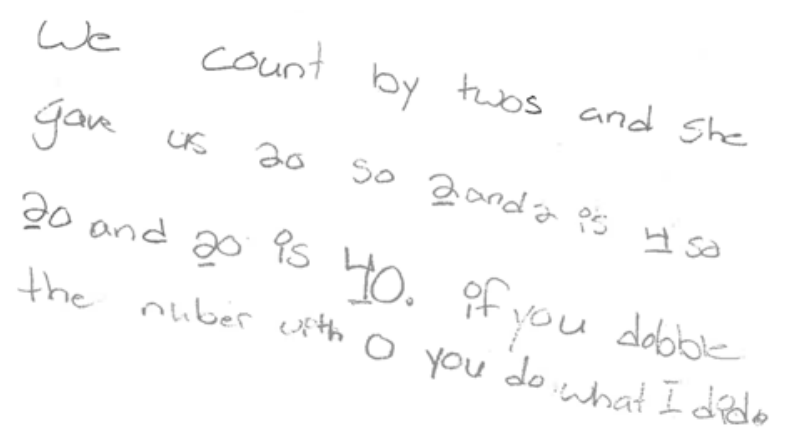

Figure 8. Example of the use of both a "counting by twos" and "doubling" strategy. 10

One of the 20 students included an answer of 40 people, with no explanation about his response. Table 4 shows the range of responses provided by students.

10 "We count by twos and gave us 20 so 2 and 2 is 4 so 20 and 20 is 40 . If you double the number with 0 you do what I did." 
Table 4. Stated strategies and types of responses among 20 students who responded " 40 " and who did not "guess" their answer.

\begin{tabular}{|c|c|c|c|c|c|c|c|}
\hline & & \multicolumn{4}{|c|}{ Stated strategy } & \multirow[t]{2}{*}{ No strategy stated } & \multirow{2}{*}{$\begin{array}{l}\text { Total numbe } \\
\text { of students }\end{array}$} \\
\hline & & Counting by $1 \mathrm{~s}$ & $\begin{array}{l}\text { Counting by } \\
\text { twos }\end{array}$ & $\begin{array}{c}20+20=40 \text { (i.e., } \\
\text { doubling or } \\
\text { counting twenty } \\
\text { two times) }\end{array}$ & $\begin{array}{l}\text { State that they } \\
\text { both "count by } \\
\text { twos" and } \\
\text { "double" }\end{array}$ & & \\
\hline \multirow{2}{*}{$\begin{array}{l}\text { Draw } \\
\text { tables/people }\end{array}$} & $\begin{array}{l}\text { With no explicit } \\
\text { verbal reference } \\
\text { to "people/chairs" } \\
\text { or "tables/desks" }\end{array}$ & 2 & 2 & - & - & & 4 \\
\hline & $\begin{array}{l}\text { With explicit } \\
\text { verbal reference } \\
\text { to "people/chairs" } \\
\text { or "tables/desks" }\end{array}$ & - & 3 & - & - & - & 3 \\
\hline \multirow{2}{*}{$\begin{array}{l}\text { No tables/people } \\
\text { drawn }\end{array}$} & $\begin{array}{l}\text { With no explicit } \\
\text { verbal reference } \\
\text { to "people/chairs" } \\
\text { or "tables/desks" }\end{array}$ & - & - & 7 & 2 & - & 9 \\
\hline & $\begin{array}{l}\text { With explicit } \\
\text { verbal reference } \\
\text { to "people/chairs" } \\
\text { or "tables/desks" }\end{array}$ & - & 1 & 2 & - & - & 3 \\
\hline \multicolumn{2}{|c|}{$\begin{array}{l}\text { Just provide the answer " } 40 " \text { with no } \\
\text { strategy articulated }\end{array}$} & - & - & - & - & 1 & 1 \\
\hline
\end{tabular}


We can conclude from Table 4 that the vast majority (20 of 21) of students were able to figure out that 40 people would be the response for how many people will sit at 20 tables. Furthermore, all but one of these 20 students used either a "counting by twos" or a "doubling" strategy, or both, just as they had done in class as a whole group. It is entirely possible that students were simply repeating the two strategies that were mentioned during the earlier whole group discussion. In fact, we can assume that at least those students who did not draw the tables/people probably used one of these strategies to find the answer, even if they didn't explicitly state so. Thirteen of the 19 students who used either a "counting by twos" or a "doubling" strategy made no explicit verbal reference to the physical problem context of "people and tables," whether they were drawing or not (although clearly, the drawing of tables is an explicit reference to tables and chairs). The other six students explicitly named people and tables in some way in their written work. It is also striking that no student who drew the problem expressed a functional strategy (doubling), suggesting that being able to draw the context of tables and chairs is not sufficient for seeing the relationship (i.e., may not support their functional thinking) or could preclude their need to find and use a functional strategy.

\subsection{Whole group discussion after small-group work: continuing to explore counting by twos and doubling as descriptions of the relationship underlying the birthday party tables problem}

Before starting the large group discussion again, Bárbara added the case of 10 tables and 20 people to the function table that she had started with the class (see Figure 3), before the children started working on their individual handouts (see Figure 9). 
$10 \quad 20$

Figure 9. Organization of the information in two columns.

57. Bárbara: Let me look through your answers... I see a lot of forty, forty (adding to the table the values 20 on the left, and 40 on the right, see Figure 10)... So if there are twenty desks... forty [people]. So, before we go any further, I want to put this together on a T-chart or a table (putting together the display shown in Figure 10).

\begin{tabular}{c|c} 
& \\
\hline 1 & 2 \\
2 & 4 \\
3 & 6 \\
10 & 20 \\
20 & 40
\end{tabular}

Figure 10. Organization of the information in a function table.

Before labeling the columns of the table, Bárbara asked the students:

58. Bárbara: How could I label these columns? What are these numbers showing?

59. Bella: Number of days.

60. Bárbara: Are we talking about number of days today (the Pennies in a jar problem the children had worked on three days before did involve days - the grandmother in the problem gave one penny to her grandchild every day; see Table 2)?

61. Students: No...

62. Bárbara: What do other people say? On Tuesday we were talking about number of days (referring to Lesson 3, Pennies in a jar)... 
63. Students: Number of tables.

We note that students stated "number of tables" and not just "tables." This suggests that students may have interpreted the variable as a quantity (number of tables) rather than an object (table), pointing to an important misconception that research has found to be present in students' thinking, but that was not evidenced by these students. Joshua said that "number of people" should be the label for the right hand column. Bárbara used the symbol \# to represent "number," explaining this to the students. The final table looked like the one shown in Figure 11. It is interesting to note that when most of the children explained their responses for the cases represented in the table and for the case they worked on in their handouts, they recontextualized the problem from a physical to a mathematical context (Carraher \& Schliemann, 2002). Then, when naming the labels for the table shown in Figure 11, they once again recontextualized the problem, from a mathematical to a physical context. This fluidity between contexts suggests that, while some students did not always explicitly note contexts in their verbal or written descriptions, these contexts were not necessarily absent from their thinking, and could be taken up — or not — as they thought it suited the particular mathematical purpose of the task.

\begin{tabular}{c|c} 
\# of tables & \# of people \\
\hline 1 & 2 \\
2 & 4 \\
3 & 6 \\
10 & 20 \\
20 & 40
\end{tabular}

Figure 11. Organization of the information in a labeled table. 
Bárbara asked the students how they got from 20 to 40 , recognizing that there might be different ways of arriving at the same answer.

64. Annita: Double the number.

65. Bárbara: Did someone do it differently?

66. Student: Counting... sometimes counting by twos.

67. Bárbara: You sometimes counted by twos. But we found some of the people who were counting by twos because we were skipping so many tables, I saw some people who got lost when they do that. But it is another strategy definitely... Shay, did you use the strategy you had used before? You did not call it doubling; you said you were adding the number again (see line 47 above)?

68. Shay: I did a number line (she used a number line to add 20 and 20, see Figure 7).

During the conversation, James stated that he had used the same strategy as Shay $(20+20=40)$. Bárbara then proceeded to propose bigger and bigger cases for the students to work with. She included 30 in the column with the number of tables and asked the students for the number that should be written in the column next to it. Thomas responded 60 almost immediately.

69. Bárbara: How did you to that so fast?

70. Thomas: Because three plus three is six and 30 plus 30 is 60 .

Bárbara added 40 to the column on the left (quantity of tables). Thomas used the same strategy to answer 80 . Then, Bárbara added 1,000,000 to the column on the left, which students identified as "one million." When Frank wrote 2,000,000 in the column on the right to correspond with 1,000,000 tables, Bárbara asked Frank to explain to his peers how he got that answer.

71. Frank: I doubled 1,000,000. 
The excerpts above continue to emphasize that students are fluently working with the numbers presented to them. The excerpts also indicate that once bigger numbers are presented to them $(30 ; 40 ; 1,000,000)$, students move away from a counting by twos strategy and instead focus on a doubling strategy. In both strategies — counting by twos and doubling for smaller numbers, and doubling for bigger numbers - the excerpts provide evidence that students have recontextualized the problem from a physical to a mathematical context, creating their own meaning for it. Bárbara then proceeded to introduce a letter as a representation for a variable. ${ }^{11}$

72. Bárbara: What if there are $z$ tables (adding $z$ to the table)?... First of all, what does $z$ tables mean?

73. Bella: It could be "zelian" tables (perhaps looking for a "number word" that rhymes with million, because one "million" had been the last case discussed). It could be any number.

74. Bárbara: If I say that there are $z$ tables, $z$ number of tables, how many numbers of people are there? What is the rule? How can I get from here ( $z$ tables) to here (pointing to the right hand column)? Think of what you were doing in your head... Does anyone have a solution in your head? I am gonna ask for many solutions because there are different ways of showing this.

Annita said that there were $z$ people because $z$ meant "any number." Bárbara referred back to the Pennies in a jar problem (Lesson 3, see Table 2) because, for the identity function representing the relationship in the Pennies in a jar problem, corresponding values or letters representing an unknown quantity recorded in the function table were the same. But, as Bárbara pointed out, in this problem (Birthday Party Tables), corresponding values are not the same, so the variable is changing from one column to the next.

\footnotetext{
${ }^{11}$ Introducing variable notation in every lesson was considered in the design of the classroom teaching experiment.
} 
75. Bárbara: ... so Annita, I get where you are coming from but if I write $z$, it could mean that it is the same number. It could mean that if I say a 10 here (pointing out the column on the left), it is gonna be 10 here, on this side (pointing to the column on the right). So, what could I write so that no one gets confused? What could I put?

76. Joshua: $z$.

77. Bárbara: That was Annita's solution. Who else has a different solution? Joshua proposed doubling 26. Our interpretation is that, like other children in our study (see Brizuela et al, 2015a; Brizuela et al., 2015b), James assigned a specific value to $z$ based on its ordinal position in the alphabet (i.e., $z$ is the $26^{\text {th }}$ letter in the alphabet).

78. Bárbara: Is that your rule? What was the rule people said? Doubling?... So if $z$ is 26 , what should I put on the other side (on the right hand column)?

Joshua started working on 26 plus 26 with another member of the research team and the class returned to other ways to show the relationship between number of tables and number of people using the letter $z$. Notice that even though Joshua does not know how much "double 26 " is and had a hard time figuring out this computation, he knows that what he has to do in this function is double the value of $z$ (which for him is fixed at 26).

79. Bárbara: How could I show that I am doubling $z$ (picking up on Joshua's point that he is doubling twenty-six)?... What do I have to do to $z$ to get the number of people?... Any other ideas?

\section{$\cdots$}

80. Jayla: Doubled $z$.

81. Bárbara: How would I show that?... Could you write that?

82. Jayla: An equation. 
83. Bárbara: And, what would the equation look like?

Annita proposed that double $z$ could be written with two $z$ and Bárbara wrote $z \mathrm{z}$ in the right hand column, next to $z$ tables.

84. Bárbara: Does it look like something that you would like or you would agree with? ... James?

85. James: You could put $z$ plus $z$. (Bárbara added " $z+z$ " next to $z$ z)

86. James: ... equals $z$.

The students' regular classroom teacher intervened.

87. Teacher: James, when we double two, would we say two plus two equals two? (Pointing at the table with particular cases.)

88. James: No.

89. Teacher: So, does it make sense, $z+z$ equals $z$ ?

90. James: No.

At this point, there were two options on the flip chart next to $z: z \quad z$ and $z+z$. Before ending the class, Bárbara explained to the students, regarding the notation $z$ z, that when we want to add two letters, we have to write + between them, otherwise some people might think that the $z$ would be multiplying with another z. Finally, Bárbara asked the students to ask questions before leaving and some students expressed confusion about the idea of adding two letters. One of them expressed "How can $z+z$ equal something?" Another said "so it is [as if] like letters were numbers...." In this final excerpt of the lesson, note that once again students have shifted away from a recursive counting by twos strategy and instead focus on a functional doubling strategy.

\section{DISCUSSION AND CONCLUSIONS}


Our study provides evidence of students' ideas concerning functional relationships. In terms of this paper's research questions, many children clearly understood the functional relationship, and had different ways of expressing their understandings. Further, they looked to generalize this relationship as a correspondence rule. They expressed this generalization by talking about the relationship between both variables in terms of doubling (or adding the same number to itself). There was some variation depending on the magnitude of the values used—as mentioned before, the doubling strategy tended to be the only one used for larger values and for variable notation. In addition, in expressing their thinking about functional relationships, children tended to recontextualize the problem from a physical to a mathematical context and back.

The section that follows is focused on the role of context and recontextualizing in mathematical tasks. In the following section we describe the two different strategies that students adopt when examining function data in a problem intended for them to explore correspondence relationships - counting by twos and doubling. In the last section we describe the representations students used. We finish with some further conclusions from our study in the fourth section. Role of Context and of Recontextualizing

Children in our study were introduced to the use of a function table to organize data sets in a mathematical context. In order to put together the table, they first recontextualized from a physical to a mathematical context. Then, when needing to label the table that only contained numbers, children further recontextualized the problem - this time from a mathematical to a physical context—-by indicating the physical quantities represented by the values (e.g., "number of tables" and "number of people"). Carraher and Schliemann (2002) highlight that, Research sorely needs to find theoretical room for contexts that are not reducible to physical settings or social structures to which the student is passively subjected... much of 
the work in developing flexible mathematical knowledge depends on our ability to recontextualize problems - to see them from diverse and fresh points of view and to draw upon our former experience, including formal mathematical learning. Mathematization is not to be opposed to contextualization, since it always involves thinking in contexts. Even the apparently context-free activity of applying syntax transformation rules to algebraic expressions can involve meaningful contexts. (p. 142)

We argue here that the children in our study were involved in both mathematization and contextualization through the process of recontextualizing the problem they were working on. In the data we have described, the children mathematized the problem by identifying the recursive pattern ("counting by twos") or the functional relationships ("doubling"), recontextualizing the problem (Carraher \& Schliemann, 2002) from a physical to a mathematical context and focusing on the numerical relationship, with no need to explicitly make a connection back to the birthday party tables problem context. That is, they shifted from a problem posed in a physical context and recontextualized it into a purely mathematical context. In addition, they were also able to interact with the organization of the information in a two-column format, with the number of tables organized in the left hand column, and the number of chairs/people in the right hand column.

Some students approached the problem by alluding just to the numbers involved. We argue that this case, as mentioned before, can be viewed as an example of recontextualization (Carraher \& Schliemann, 2002). As Carraher and Schliemann state, "it is important not to think of context solely in terms of physical or social settings and their constraints. To do so would deny the existence of mathematical contexts" (p. 142). Moreover, we note that this very activity of moving across contexts, particularly of recontextualizing a problem situation into a 
mathematical context, is an important mathematical activity for students. The US Common Core Standards for Mathematical Practice (CCSSI, 2010) specifically argues that students should be able to contextualize and decontextualize as they make sense of quantities and their relationships: Mathematically proficient students....bring two complementary abilities to bear on problems involving quantitative relationships: the ability to decontextualize - to abstract a given situation and represent it symbolically and manipulate the representing symbols as if they have a life of their own, without necessarily attending to their referents - and the ability to contextualize, to pause as needed during the manipulation process in order to probe into the referents for the symbols involved.

While many of the examples of recontextualization provided by Carraher and Schliemann (2002) involve either moving across different physical contexts, or recontextualizing a mathematical context into a physical context, we argue that the same recontextualization is required of the children who move from a physical context to a mathematical one.

While we might assume that providing a physical context (tables/desks and chairs/people) for the children would allow them to create meaning for the $y=2 x$ function they were working with, the data we provide here reminds us of the fact that we should not assume that we necessarily share contexts with children. As Table 4 shows, very few of the children who identified a functional relationship (doubling) referred explicitly to the physical context (two out of 21 children). Once again, as Carraher and Schliemann (2002) remind us,

because contexts are not fully constituted by their physical properties but always involve issues of meaning and interpretation, we cannot assume that children sharing the same physical settings as ourselves will be interpreting problems in the same contexts that we do. (p. 143) 
Nemirovsky (1996) makes a similar point when he highlights that,

Often problems are characterized as being decontextualized because they are just about numbers (as opposed to quantities or measures of specific things), as if all the rich background of ideas and experiences that students develop around numbers could not offer a context. I see the origin of this mistaken notion in the assumption that the context belongs to the formulation of the problem, ignoring that real contexts are to be found in the experience of the problem solvers. (p. 313)

\section{Types of Relationships Children Noticed}

Some of the students in the class began to articulate a relationship between two quantities (for whatever number [of tables], I double that number [to get the number of chairs/people]). Others viewed the relationship recursively, identifying "counting by twos" or "add two" as the relationship that describes the progression from one row to the next in the table.

As presented to the children, the problem was initially conceptualized as "two chairs can be placed at each one of the tables." The underlying function, $y=2 x$, can be represented as shown in Figure 3, where we see two chairs seated at each table. The counting by twos strategy that some of the children used is consistent with this representation: I count by twos however many tables there are. For instance, if there are 5 tables, I count by twos 5 times. As noted above, however, most children made no reference to people or tables.

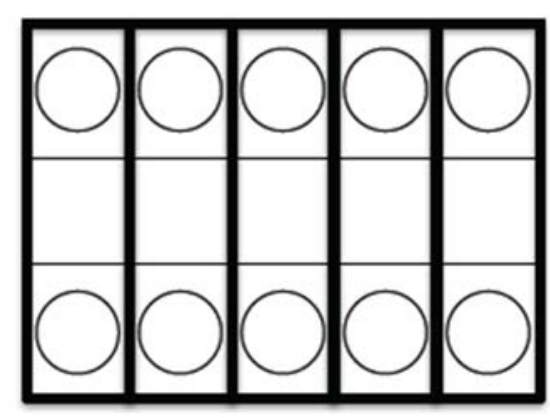

Figure 3. A possible representation for the $y=2 x$ problem for the particular case $x=5$. 
The "doubling" or "counting twice of the number [of tables]" strategy adopted by some children could be represented as shown in Figure 4. Of course, it is unlikely that the children themselves would have represented the problem in this way. It is more likely that children found a general rule that, in all cases, explained the relationship between the pairs of values: "if you count the first number two times, you get the second number."

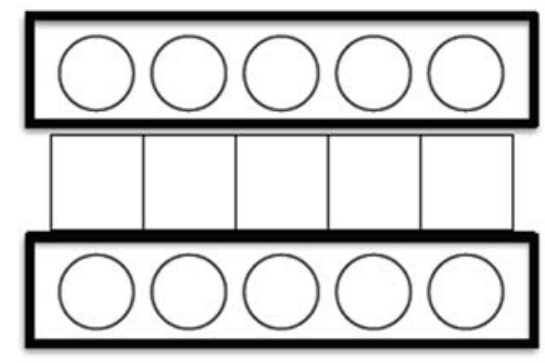

Figure 4. Another representation for the $y=2 x$ problem, when it is transformed into $y=x+x$ for the particular case $x=5$.

The two strategies indicate two distinct and equally valid entry points into the Birthday Party Tables problem for children, although there are mathematical limitations with recursive thinking at this level. While the problem was presented in terms of "two children per table" (see line 2), the children explored the relationship numerically and ended up transforming the problem into an $x+x$ (additive) relationship. This orientation is closer to the way in which the multiplicative structure $(2 x)$ is introduced in these early elementary school grades, so it seems reasonable for children to view the relationship in this way. That is, children at this grade level learn about "doubling" and "doubles" as an operation of adding the same number to itself and are not taught this as multiplying a number by two. A doubling strategy could be further articulated as "I am doubling because no matter how many tables there are, if I double that number, I will know how many people are sitting at that number of tables.” 
With smaller numbers (1-20), children tended to use both the recursive (counting by twos) and the functional strategies. Once the classroom instructor shifted towards using bigger numbers $(30 ; 40 ; 1,000,000)$ and variable notation, students shifted to using the functional strategy. This provides additional evidence for the approach of using "far values" as well as variables to support the use of functional thinking among children (see e.g., Schliemann, Carraher, \& Brizuela, 2007).

\section{Representations Used by Children}

Students approached the problem both by making the specifics of the problem context explicit (for example, by either drawing "desks" and "people" or by naming them explicitly in their written work) or by alluding just to the numbers involved. Some of the participants in the class were comfortable using natural language to express a relationship as either a recursive pattern ("counting by twos") or as a functional relationship ("doubling"). As stated earlier, they

tended to express the strategy as "counting by twos" when dealing with smaller numbers, and as "doubling" when dealing with larger numbers. The students seemed comfortable using the tabular representation to organize the problem's information. They used both drawings and natural language to express and justify the relationships between the two varying quantities. In terms of the magnitudes of the numbers they worked with, students were comfortable working with numbers presented to them, even far values (up to one million). Moreover, they attempted to express a general functional relationship using variable notation in meaningful ways.

\section{Further Conclusions}

Finally, we argue that the design of the classroom teaching experiment allowed children to identify and explore the functional relationship, particularly with the careful introduction of far values for the number of tables. The classroom teaching experiment provided children with 
the opportunity to check if the generalizations articulated were valid or not by trying out different values, both smaller and larger, as well as to justify their own arguments with other particular cases. Further, when variable notation (i.e., z) was introduced as "any number"- the second lesson in our classroom teaching experiment that they had contact with letters in algebraic contexts - some students were able to use variable notation to articulate an algebraic expression that described the general rule. This is particularly interesting because they were not familiar with algebraic symbolism but were able to make sense of variable notation in this context.

In Brizuela et al. (2015a, 2015b) and in Blanton et al. (2015) we report on the evolution of understandings among students who participated in this teaching experiment. In future work, we hope to compare students' work on the Birthday Party Tables problem with their work on other problems from our teaching experiment, both through interview and classroom data.

\section{ACKNOWLEDGEMENTS}

The research reported here was supported in part by the National Science Foundation under DRK-12 Award\#1154355. Any opinions, findings, and conclusions or recommendations expressed in this material are those of the authors and do not necessarily reflect the views of the National Science Foundation.

\section{REFERENCES}

Ali, O., \& Alsayed, N. (2010). The effectiveness of geometric representative approach in developing algebraic thinking of fourth grade students. Procedia Social and Behavioral Sciences, 8, 256-263. 
Australian Curriculum, Assessment and Reporting Authority (2011). Available at http://www.australiancurriculum.edu.au/

Bednarz, N., Kieran, C., \& Lee, L. (1996). Approaches to algebra. Perspectives for seeing. Harmondsworth, Middlesex: BBC and Penguin Books Ltd.

Blanton, M., Brizuela, B., Gardiner, A., Sawrey, K., \& Newman-Owens, A. (2015). A learning trajectory in six-year-olds' thinking about generalizing algebraic relationships in functions. Journal for Research in Mathematics Education, 46(5).

Blanton, M., \& Kaput, J. (2004). Elementary grades students' capacity for functional thinking. In M. Johnsen \& A. Berit (Eds.), Proceedings of the 28th International Group of the Psicology of Mathematics Education (Vol. 2, pp. 135-142). Bergen, Norway: Bergen University College.

Blanton, M., \& Kaput, J. (2011). Functional thinking as a route into algebra in the elementary grades. In J. Cai \& E. Knuth (Eds.), Early algebraization, advances in mathematics education (pp. 5-23). Berlín, Germany: Springer. DOI 10.1007/978-3-642-17735-4_2

Blanton, M., Levi, L., Crites, T., \& Dougherty, B. (2011). Developing essential understanding of algebraic thinking for teaching mathematics in Grades 3-5. Reston, VA: NCTM.

Blanton, M., Stephens, A., Knuth, E., Gardiner, A., Isler, I., \& Kim, J. (2015). The development of children's algebraic thinking: The impact of a comprehensive early algebra intervention in third grade. Journal for Research in Mathematics Education, 46(1), 39-87.

Brizuela, B. M., \& Alvarado, M. (2010). First graders' work on additive problems with the use of different notational tools. Revista IRICE Nueva Época, 21, 37-44.

Brizuela, B. M., Blanton, M., Gardiner, A. M., Newman-Owens, A., \& Sawrey, K., (2015a). A 
first grade student's exploration of variable and variable notation / Una alumna de primer grado explora las variables y su notación. Estudios de Psicología: Studies in Psychology, 36(1), 138-165.

Brizuela, B. M., Blanton, M., Sawrey, K., Newman-Owens, A. M., \& Gardiner, A. (2015b). Children's use of variables and variable notation to represent their algebraic ideas. Mathematical Thinking and Learning, 17, 1-30.

Brizuela, B. M., \& Earnest, D. (2008). Multiple notational systems and algebraic understandings: The case of the "best deal" problem. In J. J. Kaput, D. W. Carraher, \& M. Blanton (Eds.), Algebra in the early grades (pp. 273-301). Mahwah, NJ: Lawrence Erlbaum and Associates.

Brizuela, B. M., \& Lara-Roth, S. (2002). Additive relations and function tables. Journal of Mathematical Behavior, 20(3), 309-319.

Brizuela, B. M., \& Martinez, M. V. (2012). Aprendizaje de la comparación de funciones lineales. In M. Carretero, J. A. Castorina, \& A. Barreiro (Eds.), Desarrollo cognitivo y educación: procesos de conocimiento y contenidos específicos (Vol. 2, pp. 263-286). Buenos Aires: Editorial Paidós.

Cai, J., \& Knuth, E. (2011). Early algebraization, advances in mathematics education. Berlín, Germany: Springer.

Canavaro, A. P. (2009). El pensamiento algebraico en el aprendizaje de la Matemática los primeros años. Quadrante, 16(2), 81-118.

Cañadas, M. C., Castro E., \& Castro, E. (2008). Patrones, generalización y estrategias inductivas de estudiantes de $3^{\circ}$ y $4^{\circ}$ de Educación Secundaria Obligatoria en el problema de las baldosas. PNA, 2(3), 137-151. 
Carraher, D. W., Martinez, M. V., \& Schliemann, A. D. (2008). Early algebra and mathematical generalization. ZDM - The International Journal on Mathematics Education (formerly Zentralblatt fur Didaktik der Mathematik), 40(1), 3-22.

Carraher, D. W., \& Schliemann, A. D. (2002). Is everyday mathematics truly relevant to mathematics education? In J. Moshkovich \& M. Brenner (Eds.) Everyday Mathematics. Monographs of the Journal for Research in Mathematics Education, 11, 131-153.

Carraher, D. W., \& Schliemann, A. D. (2007). Early algebra and algebraic reasoning. In F. Lester (Ed.), Handbook of research in mathematics education (pp. 669-705). Greenwich, United Kingdom: Information Age Publishing.

Carraher, D. W., Schliemann, A. D., Brizuela, B. M., \& Earnest, D. (2006). Arithmetic and algebra in early mathematics education. Journal for Research in Mathematics Education, 37, 87-115.

Confrey, J., \& Smith, E. (1995). Splitting, covariation, and their role in the development of exponential functions. Journal for Research in Mathematics Education, 26(1), 66-86.

Chevallard, Y. (1989). Le passage de l'arithmétique a l'algébrique dans l'enseignement des mathématiques au collège [The passage from the arithmetical to the algebraic in the teaching of high school mathematics]. Petit $X, 19,43-72$.

Common Core State Standards Initiative. (2010). Common Core State Standards for Mathematics. Common Core State Standards (College- and Career-Readiness Standards and K-12 Standards in English Language Arts and Math). Washington, DC: National Governors Association Center for Best Practices and the Council of Chief State School Officers. Retrieved from http://www.corestandards.org. 
Doorman, M., \& Drijvers, P. (2011). Algebra in functions. In P. Drijvers (Ed.), Secondary algebra education (pp. 119-135). Rotterdam, The Netherlands: Sense Publishers.

Dougherty, B. (2008). Measure up: A quantitative view of early algebra. In J. J. Kaput, D. W. Carraher, \& M. Blanton (Eds.), Algebra in the early grades (pp. 389-412). Mahwah, NJ: Lawrence Erlbaum and Associates.

Drijvers, P., Goddijn, , A. A. D., \& Kindt, M. (2011). Patterns and formulas. In P. Drijvers (Ed.), Secondary algebra education (pp. 89-100). Rotterdam, The Netherlands: Sense Publishers.

Drijvers, P., \& Hendrikus, M. (2003). Learning algebra in a computer algebra environment: design research on the understanding of the concept or parameter. Unpublished Doctoral Thesis. Utrecht, The Netherlands: Universidad de Utrecht. Downloaded April $7^{\text {th }}, 2011$ in http://www.library.uu.nl/digoarchief/dip/diss/2003-0925101838/in.houd.htm

Ellis, A. B. (2007). The influence of reasoning with emergent quantities on students' generalizations. Cognition and Instruction 25(4), 439-478.

Ensley, D. E., \& Crawley, J. W. (2006). Discrete mathematics. Mathematical reasoning and proof with puzzles, patterns and games. New York, NJ: Wiley.

Freudenthal, H. (1983). Didactical phenomenology of mathematical structures. Dordrecht, The Netherlands: Academic Publishers Group.

Hamley, H. R. (1934). Relational and functional thinking in mathematics: The 9th Yearbook of NCTM. New York: Bureau of Publications, Teachers College, Columbia University. Johnsonbaugh, R. (2005). Matemáticas discretas. México DF: Prentice-Hall Hispanoamericana. 
Kelly, A. E. (2003). Theme issue: The role of design in educational research. Educational Researcher, 32(1), 3-4.

Kieran, C. (1996). The changing face of school algebra. In C. Alsina, J. Álvarez, B. Hodgson, C. Laborde, \& A. Pérez (Eds.), Proceedings of 8th International Congress on Mathematical Education: Selected lectures (pp. 271-290). Sevilla, Spain: SAEM Thales.

Kieran, C. (2004). The core of algebra: Reflections on its main activities. In K. Stacey, H. Chick, \& M. Kendal (Eds.), The future of teaching and learning of algebra: The 12th ICMI Study (pp. 21-33). Dordrecht, The Netherlands: Kluwer.

MacGregor, M., \& Stacey, K. (1995). The effect of different approaches to algebra on students' perceptions of functional relationships. Mathematics Education Research Journal, 7(1), 69-85.

Martinez, M. V., \& Brizuela, B. M. (2006). A third grader's way of thinking about linear function tables. Journal of Mathematical Behavior, 25(4), 285-298.

Mason, J., Graham, A., Pimm, D., \& Gowar, N. (1985). Routes to/roots of algebra. Milton Keynes, United Kingdom: The Open University Press.

Merino, E., Cañadas, M. C., \& Molina, M. (2013). Uso de representaciones y patrones por alumnos de quinto de educación primaria en una tarea de generalización. Edma 0-6: Educación Matemática en la Infancia, 2(1), 24-40.

Molina, M., \& Ambrose, R. (2008). From an operational to a relational conception of the equal sign. Thirds graders' developing algebraic thinking. Focus on Learning Problems in Mathematics, 30(1), 61-80. 
Moss, J., \& Beatty, R. (2006). Knowledge building in mathematics: supporting collaborative learning in pattern problems. Computer-Supported Collaborative Learning, 1, 441-465.

Moss, J., \& Beatty, R. (2010). Knowledge building and mathematics: Shifting the responsibility for knowledge advancement and engagement. Canadian Journal of Learning and Technology on Knowledge Building, 36(1). Available at http://www.cjlt.ca/index.php/cjlt/article/view/575/277

Moss, J., Beatty, R., Shillolo, G., \& Barkin, S. (2008). What is your theory? What is your rule? Fourth graders build their understanding of patterns and functions on a collaborative database. In C. Greenes (Ed.), Algebra and algebraic thinking in school mathematics: The National Council of Teachers of Mathematics 70th Yearbook (2008) (pp. 155-168). Reston, VA: NCTM.

Moss, J., \& McNab, S. (2011). An approach to geometric and numeric patterning that fosters second grade students' reasoning and generalizing about functions and co-variation. In J. Cai, \& E. Knuth (Eds.), Early algebraization, advances in mathematics education (pp. 277-301). Berlin, Germany: Springer.

National Mathematics Advisory Panel. (2008). Foundations for success: The final report of the National Mathematics Advisory Panel. Washington, DC: U.S. Department of Education.

National Council of Teachers of Mathematics. (2000). Principles and standards for school mathematics. Reston, VA: Author.

National Council of Teachers of Mathematics. (2006). Curriculum focal points for prekindergarten through grade 8 mathematics: A quest for coherence. Reston, VA: Author. 
Nemirovsky, R. (1996). A functional approach to algebra: Two issues that emerge. In N. Bednarz, C. Kieran, L. Lee (Eds.), Approaches to algebra: Perspectives for research and teaching (pp. 295-313). Dordrecht, The Netherlands: Kluwer Academic Publishers.

Ontario Ministry of Education and Training. (2005). The Ontario curriculum, grades 1-8: Mathematics, revised. Ontario, Canada: Queen's Printer.

Pimentel, T. (2010). O conhecimento matemático e didáctico, com incidência no pensamento algébrico, de professores do primeiro ciclo do ensino básico: que relações com um programa de formação contínua? Ph Doctoral Thesis. Braga, Portugal: Universidade do Minho.

Pisot, C., \& Zamansky, M. (1996). Matemáticas generales. Álgebra-Análisis. Barcelona, Spain: Montaner y Simon.

Radford, L. (2011). Grade 2 Students' Non-Symbolic Algebraic Thinking. In J. Cai \& E. Knuth (Eds.), Early algebraization: A global dialogue from multiple perspectives. Advances in Mathematics Education Monograph Series (pp. 303-322). New York: Springer.

Rico, L. (2006). La competencia matemática en PISA. PNA, 1(2), 47-66.

Schliemann, A. D., Carraher, D. W., \& Brizuela, B. M. (2007). Bringing out the algebraic character of arithmetic: From children's ideas to classroom practice. Mahwah, NJ: Lawrence Erlbaum and Associates.

Schliemann, A. D., Carraher, D. W., \& Brizuela, B. M. (2012). Algebra in Elementary School. In Coulange, L., Drouhard, J.-P., Dorier, J.-L., Robert, A. (Eds.) Recherches en Didactique des Mathématiques, Numéro spécial hors-série, Enseignement de l'algèbre élémentaire: bilan et perspectives (pp. 103-118). Grenoble: La Pensée Sauvage. 
Schwartz, J. (1990). Getting students to function in and with algebra. In G. Harel \& E.

Dubinsky (Eds.), The concept of function: Aspects of Epistemology and Pedagogy (pp. 261-289). Washington, DC: Mathematics Associations of America.

Seldon, A., \& Seldon, J. (1992). Research perspectives on conceptions of function: Summary and overview. In E. Dubinsky \& G. Harel (Eds.), Concept of function: Aspects of epistemology and pedagogy (pp. 1-21). Washington, DC: Mathematical Association of America.

Usiskin, Z. (1999). Conceptions of school algebra and uses of variables. In B. Moses (Ed.), Algebraic thinking, Grades K-12: Readings from NCTM’s school-based journals and other publications (pp. 7-13). Reston, VA: National Council of Teachers of Mathematics.

Warren, E. (2000). Visualisation and the development of early understanding in algebra. In T. Nakahara, M. Koyama (Eds.), Proceedings of the 24th conference of the International Group for the Psychology of Mathematics Education (vol. 4, pp. 273-280). Hiroshima, Japan: PME.

Warren, E., \& Cooper, T. (2005). Introducing functional thinking in year 2: A case study of early algebra teaching. Issues in Early Childhood, 6(2), 150-162.

Warren, E., Miller, J., \& Cooper, T. J. (2013). Exploring young students' functional thinking. PNA, 7(2), 75-84.

Watanabe, T. (2008). Algebra in elementary school: A Japanese perspective. In C. E. Greenes \& R. Rubenstein (Eds.), Algebra and algebraic Thinking in school mathematics (pp. 183-193). Reston, VA: NCTM. 